\title{
Star and Lyric Poet in ModernArt World Xu Beihong's Assessment on Ren Bonian
}

\author{
Yang Guisi \\ Renmin University of China,Beijing,100086,China \\ Guisiyang1972@163.com
}

\begin{abstract}
:
As one of earliest and detailed researcher of artist Ren Bonian, $\mathrm{Xu}$ Beihongvisited Ren Bonian's descendants, hold exhibitions for his works, wrote articles for Ren Bonian and collected a lots of Ren Bonian's work. In the eye of Xu Beihong, Ren Bonian was an apprenticed creator, he was good at painting techniques and using colors, Ren Bonian was acclaimed as a great talented painter. And $\mathrm{Xu}$ Beihong commend him as star and lyric poet in art world.
\end{abstract}

Key Words: $\mathrm{Xu}$ BeihongRen Bonian Learning from Nature ObservationGreat genius

It should be said, $\mathrm{Xu}$ Beihong was the earliest and detailed researcher of artist Ren Bonian.

$\mathrm{Xu}$ Beihongdid the on-the-spot investigation, and visited Ren Bonian's descendants, In 1928, Xu Beihong and his friend $\mathrm{Wu}$ Zhongxiong visited Ren Bonian's son Ren Jinshu.[1]
November, 1938, Xu Beihong hold an exhibitionnamed "Chinese painting show" in Feng Pingshan library, works on display including paintings finished by Ren Bonian and Xu Beihong.[2]

In 1950, Xu Beihong wrote article of Ren Bonian's biography, it was the first lifetime research article, this is the important related reference material for contemporary researchers.

$\mathrm{Xu}$ was the most important collector of Ren Bonian's work. Xu Collected dozens of Ren's work, in the death of the previous week, $\mathrm{Xu}$ purchased 4 pieces of Ren Bonian's painting.[3]

$\mathrm{Xu}$ Beihong regarded, For 300 years of Chinese painters, except Ren Bonianand $\mathrm{Wu}$ Youru, almost leavingthenull name (Xu, On revival Chinese Art Movement, 1948 ) in the painters of modern and contemporary, Ren Bonian should be the No.1(Xu, On Chinese Painting); RenBonian should be the first place after Qiu Shizhou. (Xu Beihong, Ren Bonian's Biography) 
Famous artists, social activist Cai Ruohong once said: While Xu Beihong lived, we talk about painting, he always refer to Ren Bonian; if we visited Xu's home, he was bound to hung up Ren Bonian's works which he collected for us enjoying; and he read the art works with relish, appreciate advantages of Ren Bonian's painting.[4]

\section{Why Xu Beihong was so adored Ren Bonian?}

In the first place, $\mathrm{Xu}$ Beihong contact early Ren Bonian's work. Xu Beihong's father Xu Zhangda was fond of Ren Bonian's work. the flower and bird painting of Xu Zhangda's was influenced by Xu Wei and Ren Bonian. In the artcle of Ren Bonian's Biography, Xu refer to, when he was a child, his father went to city, when he came back, he replicated one of Ren Bonian's Zhong Kui Chopping at a Tree, In that painting, the shape of tree seems like little devils, they all get entangled together, $\mathrm{Xu}$ was very impressed by this painting. Xu's friend $\mathrm{Wu}$ Zhongxiong's grandfather $\mathrm{Wu}$ Shaoqing tookRen's daughter Ren Yuhua as second wife, $\mathrm{Xu}$ Beihong and $\mathrm{Wu}$ Zhongxiongenjoy Ren Bonian's work, and $\mathrm{Wu}$ Zhongxionggive some works as present to $\mathrm{Xu}$, and they visited Ren's Son Ren Jinshuin the summer of 1928.

For further analysis, we can find the effect of Ren Bonian's work on Xu beihong from Ren Bonian's biographywrote by $\mathrm{Xu}$, related article, and annotations on the works of Ren Bonian.

\section{Learning from Nature}

In the work of Ren Bonian's biography, $\mathrm{Xu}$ introduced, when Ren Bonian reached in Shanghai, In the earliest, he make a living by imitating Ren Xiong's work, which recognized by RenXiong, he was very appreciative of Ren Bonian's talents, and then introduced him learning painting with Ren Xun. The family of Ren have a deep relationship with Ming dynasty painter Chen Hongshou.[5] So Ren Bonianalso learning from Chen's method, got traditional and orthodox school of Chinese painting. He got Zhe School's tradition, withcarefully observationand painting, at last, Ren Bonian substituted his predecessors. Ren Xiong's son $\mathrm{Li}$ Fan(Ren Yu) was good at literati paintings, so his work was not like his father and uncles, vulgar and spicy, who has great influence on Ren Bonian's painting. In another article of Xu Beihong, he said, with regard to Chinese painting, I insistence onrealismpainting style of Song dynasty.

$\mathrm{Xu}$ Beihong thought, as for the contribution of Chinese painting, the most important was birds and flowers in Songdynasty. Art works in Song dynastywere nature and real, with life and characteristic. Like the works of $\mathrm{Xu} \mathrm{Xi,}$ 
Huang Quan, Huang Jucai and Yi Yuanji, they were really the miraclein art history, they were ideal realism.

\section{Observe the Subtle}

$\mathrm{Xu}$ Beihong said, the teacher of drawingshould bereal object, but not copies of draft. Painter should depict loved and favourite themes, could not took other's eye as oneself observation. So, Xu Beihongpay attention to painter's observational ability. When he drawing a picture, he would stand by the wall, or sit on the floor, or bend the body forwards and downwards, watch carefully on them. In 1920, when he went to Europe, as long aswell-known zoo, he would to visiting. When he was in Germany, he took sketch books for depicting animals in the zoo. So, He thought the Chinese painting skill book the Mustard Seed Garden was a curse for Chinese painting.

Ren Bonian was commended by $\mathrm{Xu}$ Beihongfor his keep under observation and carefully description[6], Ren Bonian used to descript Wu Changshuo, Sha Fu, $\mathrm{Hu}$ Gongshou, Zhao Zhiqian, Xu Gu, $\mathrm{Hu}$ 's wife, other friends and relatives, His paintings capture the essence of those people, they came from his daily observation. Among them, Wu Changshuo's portraitwere about 5 or 6 pieces, and each piece was different,represent different moods and personality in different times.

\section{Based on Figure Painting, Broad and Fine}

$\mathrm{Xu}$ believe, the subject of painting learner should be in chronological order, first, figure painting, it should reflectedhuman's activities.Second, animal, flowers and birds, at last, landscape, as landscape painting was an integrated art, when you were short of some kind of basic skill, the defects would eventually be exposed. If we want to revive Chinese painting, we should comply with this order. In all kinds of painting subjects, he especially pay attention on figure painting.In his article On revival Chinese Art Movement, he emphasis, firstly, figure painting, reflectedhuman's activities, regardless of old or new.[7]

As for Ren Bonian's figure painting, it should be took as milestone in art history. He was good at portrait painting, under his father's strictteaching, he has very good basic skills of depicting figures and portrait.

$\mathrm{Xu}$ always praise Ren Bonian's figure painting, eg, Zhong Kui chopping at a tree, the Eight Immortals, Magucollected by $\mathrm{Wu}$ Zhongxiong, and Nine oldercollected by himself. Wu's sage of painting , Emperor Taizongseek knowledgecollected by Zhang Chengwang, and other figure painting. Moreover, $\mathrm{Xu}$ was highly admirationfor painter with comprehensive techniques, he thought Chen Hongshou mastered all 
kinds of painting subject,figure painting, flowers and birds and landscape, his painting all have personal style, he should be regarded asgreat master of art history. As for Ren Bonian was a painter like Chen Hongshou, he was based on figure painting, but with broad and finepainting knowledge.

\section{Expert inColoring}

In the article of Talking about Art, among modern and contemporary painters, Ren was the first place who was expert incoloring. [8]

Ren was good at using different red color, besides traditional red colors, like cinnabar, carmine, he also make use of magenta that not often used by predecessors. He use magenta to describe maple leaves, narcissus, Hong Lin and so on. Ren's ink and color painting seems more better, he like use fastdrying ink and light color to describe beauty of nature, otherwise, he also expert at using color powders. Painter Wang Xuetao once said, as for using color powders, no one can match up to Ren. He combinedcolor powders and different colors, come into being naturalistic transition of color. Ren's masterpiece The Immortal onBirthday Congratulationscan be regarded assuperlative work that combined color powders and different colors, we can see Ren's excellent color skill in this painting.

\section{Gifted in Painting}

Generally speaking, compare withtalent, $\mathrm{Xu}$ was willing to acknowledge the importance of personal efforts. $\mathrm{Xu}$ said artists should be with gift, but also need long time learning and expert advice. However, $\mathrm{Xu}$ was quite commended for Ren's gift. In the article of Ren Bonian's Biography, $\mathrm{Xu}$ thought Ren with gift given by god, he believe Ren can compare with world art masters.

Why $\mathrm{Xu}$ so admire Ren? what is the relationship between his painting and Ren's work? After watching the exhibition of Ren and $\mathrm{Xu}$, Famous Chinese painting connoisseur Ren Zhenhan thought, from those works on exhibition, we couldfindthe source of $\mathrm{Xu}$ 's Chinese painting was based on Ren's work. In spite of Xu never confess it.

Perhaps, $\mathrm{Xu}$ and Ren just mentality communicated with each other, they all learning form nature, be good at observe, and with comprehensive painting skills. In the letter $\mathrm{Xu}$ wrote to $\mathrm{Xu}$ Zhimo, $\mathrm{Xu}$ said, even my Chinese painting was not well, even though I admire the works of $\mathrm{Xu} \mathrm{Xi}$, Chen Hongshou and Ren Bonian, but I never copy the works of predecessors. From this letter, we can find, $\mathrm{Xu}$ thought himself learning form nature but not learning form elder generation. 
In his era of Ren, he was arising star in the art world of Shanghai, in the works of Ren Bonian, full of poetic, and sensuous qualities. But in the eye of $\mathrm{Xu}$ Beihong, Ren Bonian was an Star and lyric poet in art world.

\section{References}

[1] Xu Boyang \& JinShan (1991). Chronicle of XuBeihong's life.Taiwan:Artist Press.52,1991.

[2] Xu Boyang \& JinShan (1991). Chronicle of XuBeihong's life.Taiwan:Artist Press.196,1991.

[3] Gong Chanxing (2010).Ren Bonian.China:People'Fine Arts Publishing House \& Tianjin People'Fine Arts Publishing House.According to this book,there are 26 pieces of works in $\mathrm{Xu}$ Beihong Memerial Hall.

[4] Gong Chanxing (1982).Ren Bonian Research. China: Tianjin People'Fine Arts Publishing House.4,1982.

[5] Xu Qingping (2008). The Pentium in the room. China:Baihua Literature and Art Publishing House.130,2008.

[6] Ren Bonian had a work of A Portrait of Mr zhongying,which was in Dond Xiwen's home.Xu Beihong write postscript on it.

[7] Xu Qingping (2008). The Pentium in the room. China:Baihua Literature and Art Publishing House.60,2008.
[8] Xu Qingping (2008). The Pentium in the room. China:Baihua Literature and Art Publishing House.293,2008. 